\title{
Perbandingan Melatonin dan Prosedur Deprivasi Tidur untuk Persiapan Pemeriksaan Elektroensefalografi pada Anak
}

\author{
Setyo Handryastuti, ${ }^{*}$ Lenny S. Budi, ${ }^{* *}$ Irawan Mangunatmadja, ${ }^{*}$ Taralan Tambunan, ${ }^{*}$ Agus Firmansyah, ${ }^{*}$ Dwi P. Widodo, ${ }^{*}$ \\ Alifiani H. Putranti*** \\ *Departemen Ilmu Kesehatan Anak, Fakultas Kedokteran Universitas Indonesia-RS Cipto Mangunkusumo, Jakarta, ** RS Harapan \\ Bunda, Jakarta, ${ }^{* * *}$ Departemen Ilmu Kesehatan Anak Fakultas Kedokteran Universitas Diponegoro-RS Karyadi, Semarang
}

\begin{abstract}
Latar belakang. Elektroensefalografi (EEG) adalah pemeriksaan penunjang epilepsi yang dilakukan saat anak sadar dan tidur alami. Melatonin merupakan premedikasi EEG yang diharapkan menimbulkan awitan tidur lebih cepat, lama tidur cukup, tidak memengaruhi stadium tidur, timbulnya gelombang epileptiform, efek samping lebih kecil dibanding prosedur deprivasi tidur parsial (DTP).

Tujuan. 1. Mengetahui perbandingan melatonin dan prosedur DTP dalam hal awitan, stadium dan lama tidur, timbulnya gelombang epileptiform, kegagalan pemeriksaan EEG. 2. Mengetahui perbedaan efek samping pemberian melatonin dibandingkan DTP. Metode. Uji klinik acak tersamar tunggal pada 76 subyek berusia 1-18 tahun yang menjalani pemeriksaan EEG di Departemen IKA-RSCM. Subyek dibagi 2 kelompok, yaitu kelompok melatonin per oral dan DTP. Dilakukan pencatatan awitan, stadium dan durasi tidur, timbulnya gelombang epileptiform, efek samping yang timbul.

Hasil. Rerata awitan tidur kelompok DTP 42,39 menit, melatonin 33,97 menit ( $\leq \leq 0,01$ ). Rerata lama tidur kelompok DTP 22,58 menit, melatonin 25,09 menit ( $\mathrm{p}=0,144)$. Stadium tidur, timbulnya gelombang epileptiform dan efek samping pada kedua kelompok tidak berbeda bermakna.

Kesimpulan. Awitan tidur kelompok melatonin lebih cepat dibandingkan DTP. Durasi, stadium tidur, gelombang epileptiform kedua kelompok mirip dengan tidur alamiah dan tidak ada perbedaan efek samping. Kegagalan EEG pada kelompok melatonin lebih kecil dibandingkan prosedur DTP. Disimpulkan melatonin dapat digunakan sebagai premedikasi EEG pada anak. Sari Pediatri 2018;19(6):328-34
\end{abstract}

Kata kunci: premedikasi EEG, melatonin, deprivasi tidur parsial, epilepsi anak

\section{Comparison between Oral Melatonin and Partial Sleep Deprivation Procedure for Electroencephalography Preparation in Epilepsy Children}

Setyo Handryastuti, ${ }^{*}$ Lenny S. Budi, ${ }^{* *}$ Irawan Mangunatmadja, ${ }^{*}$ Taralan Tambunan, ${ }^{*}$ Agus Firmansyah, ${ }^{*}$ Dwi P. Widodo, ${ }^{*}$ Alifiani H. Putranti***

Background. Electroencephalography (EEG) is a neurodiagnostic procedure in children with epilepsy, and can be achieved if the child fell on a natural sleep. Melatonin, was a premedication following EEG procedure to produce natural sleep with minimal side effects compared to partial sleep deprivation (PSD) and other sedative agents.

Objective. 1. To compare melatonin with PTD for onset, duration, sleep stage, appearance of epileptiform activity and failure of EEG examination. 2 To know differences in side effects of oral melatonin

Method. It was a single-blinded randomized clinical trial, 76 children who were referred to EEG Unit of Cipto Mangunkusumo Hospital were evaluated. Subject were randomly assigned into two groups to receive PSD and melatonin.

Results. Mean sleep onset in PSD and melatonin group were 42.39 and 33.97 minutes $(\mathrm{p} \leq 0,01)$ respectively. Mean sleep duration in PSD and melatonin group were 22.58 and 25.09 minutes respectively ( $p>0,05)$. There were no significant differences in both sleep stage and side effects $(\mathrm{p}>0,05)$ in both groups.

Conclusions. Sleep onset was earlier in melatonin group compares to PDS group, while sleep duration was similar between each groups. There were no significant differences of sleep stages and side effects in both groups. Melatonin can be use as premedication for EEG examination in epilepsy children. Sari Pediatri 2018;19(6):328-34

Keywords: EEG premedication, melatonin, partial sleep deprivation, child epilepsy

Alamat korespondensi: DR. Dr. Setyo Handryastuti, SpA(K). Departemen Ilmu Kesehatan Anak, Fakultas Kedokteran Universitas Indonesia-RS Cipto Mangunkusumo, Jakarta email : handryabdullah@yahoo.com 
Setyo Handryastuti dkk: Perbandingan melatonin dan prosedur deprivasi tidur untuk persiapan pemeriksaan EEG

$\mathrm{E}$ lektroensefalografi (EEG) adalah suatu prosedur yang membantu diagnosis dan evaluasi pengobatan pada epilepsi anak. Diagnosis epilepsi ditegakkan berdasarkan gejala klinis, ditandai dengan bangkitan kejang yang paroksismal, berulang lebih dari 2 kali dalam kurun waktu lebih dari 24 jam dan tanpa provokasi. Pemeriksaan EEG cukup sensitif dan spesifik untuk membantu diagnosis dan klasifikasi epilepsi, menentukan fokus epileptik, serta adakah penyebaran fokus epilepsi. ${ }^{1-2}$

Rekaman EEG yang baku dimulai saat pasien dalam keadaan sadar, kemudian anak diminta untuk buka tutup mata, dilanjutkan dengan prosedur stimulasi fotik dan hiperventilasi (apabila pasien sudah dapat melakukannya). Setelah itu, lampu ruang pemeriksaan diredupkan sehingga diharapkan pasien mengantuk (drowsy), tertidur untuk beberapa saat, dan akhirnya pasien terbangun dengan sendirinya (arousal). Kondisi drowsy, arousal, stimulasi fotik, dan hiperventilasi diperlukan untuk memprovokasi timbulnya gelombang epileptiform. ${ }^{1-4}$

Perekaman EEG yang ideal mengharuskan pasien kooperatif, sebelum maupun selama pemeriksaan. Hal ini yang mengakibatkan perekaman EEG memiliki keterbatasan, terutama pada pasien anak. . $^{1,2,5-7}$

Sampai saat ini di Indonesia masih banyak digunakan obat-obat sedasi, seperti golongan benzodiazepin, klorpromazin, dan kloralhidrat untuk mendapatkan kondisi tidur pada pemeriksaan EEG. ${ }^{5-8}$ Kloralhidrat atau klorpromazin dapat memengaruhi stadium tidur sehingga anak langsung jatuh ke stadium tidur III-IV sehingga gelombang epileptiform tidak terlihat. Selain itu, pasien lebih sulit bangun sehingga observasi terhadap pasien memakan waktu yang lebih lama.

Kloralhidrat mengandung zat aktif trikloroetanol yang menekan sistem saraf pusat, dan langsung menimbulkan gelombang theta pada pasien (stadium tidur yang dalam), sehingga gelombang epilepsi tidak terlihat. Klorpromazin menekan reticular activating system (RAS) sehingga memengaruhi metabolisme basal, temperatur tubuh, tonus vasomotor, emesis, dan kesiagaan sehingga memiliki efek hipnotik. Benzodiazepin mempercepat awitan tidur, tetapi menyebabkan lama tidur berkurang. Selain itu juga menyebabkan depresi saluran nafas, menghambat munculnya gelombang epileptiform, dan munculnya gelombang beta. ${ }^{5-8}$
Mengingat efek klinis dan efek samping dari pemberian obat sedatif tersebut, maka dipikirkan pengganti yaitu prosedur deprivasi tidur parsial (DTP), untuk memperoleh kondisi tidur yang alami saat perekaman EEG anak. Prinsip deprivasi tidur parsial adalah anak ditidurkan lebih lambat dan dibangunkan lebih awal sehingga pada saat perekaman EEG kondisi tidur alami tercapai. Kondisi ini menyebabkan ketidaknyamanan bagi orangtua maupun anak sendiri, selain itu juga sering menjadi faktor penundaan dan kegagalan pemeriksaan EEG pada anak sehingga proses DTP sering dihindari. ${ }^{5-8}$

Beberapa pusat neurodiagnostik di berbagai negara menggunakan melatonin sebagai premedikasi untuk menggantikan prosedur DTP. Melatonin merupakan hormon tidur alami yang dihasilkan oleh kelenjar pineal. Penelitian Wassmer menunjukkan bahwa tidak terdapat perbedaan bermakna pada stadium tidur non-REM pada subyek yang diinduksi melatonin dengan yang dilakukan DTP. Penelitian ini menyimpulkan melatonin sama efektif dengan DTP dalam menginduksi tidur sehingga dapat digunakan sebagai pengganti deprivasi tidur pada perekaman EEG. ${ }^{8}$

Mengingat permasalahan di atas, maka dipikirkan kemungkinan pemberian melatonin sebagai pengganti DTP untuk persiapan perekaman EEG pada anak di Indonesia. Penelitian tentang pemakaian melatonin untuk persiapan perekaman EEG pada anak belum pernah dilakukan di Indonesia.-9 ${ }^{5-9}$ Tujuan penelitian : (1) mengetahui perbandingan antara premedikasi melatonin dan prosedur DTP dalam hal awitan, lama dan stadium tidur serta angka kegagalan antar 2 kelompok pada pemeriksaan EEG anak. (2) mengetahui perbedaan efek samping pemberian premedikasi melatonin dibandingkan prosedur DTP.

\section{Metode}

Penelitian uji klinik secara acak, tersamar tunggal, prospektif dilakukan secara paralel. Subyek adalah seluruh pasien epilepsi anak (usia 1 sampai 18 tahun) yang datang ke Poliklinik Neurologi Anak dan Laboratorium Elektrodiagnostik IKA-RSCM untuk pemeriksaan EEG dan memenuhi kriteria inklusi. Pasien dengan disabilitas intelektual, autisme dan gangguan pemusatan perhatian dan hiperaktif (GPPH) dieksklusi.

Randomisasi dilakukan pada subyek dan ditentukan 2 kelompok subyek penelitian, (1) kelompok 
Setyo Handryastuti dkk: Perbandingan melatonin dan prosedur deprivasi tidur untuk persiapan pemeriksaan EEG

kontrol dilakukan prosedur DTP, (2) kelompok intervensi diberikan melatonin.

Perekaman EEG pada kelompok kontrol dilakukan prosedur DTP. Berikut persiapan perekaman EEG pada kelompok kontrol, (1) usia 0-2 tahun: tidak ada hal khusus, bangunkan anak jam 6-7 pagi, keadaan bangun dipertahankan sampai perekaman EEG jam 13.00, (2) usia 2-4 tahun: bangunkan jam 5 pagi dan tetap bangun sampai perekaman jam 13.00, anak usia ini masih tidur siang pada saat perekaman, (3) usia 4-6 tahun: tidur larut (22.00 -23.00) bangunkan jam 5 pagi, tetap terjaga sampai perekaman jam 13.00, (4) Usia 6-10 tahun: jam 24.00 tidur, jam 05.00 pagi dibangunkan sampai dengan perekaman jam 13.00, (5) Usia 10-16 tahun: jam 24.00 tidur, jam 03.00 pagi dibangunkan, tetap terjaga sampai perekaman jam 09.00 .

Kelompok intervensi dilakukan perekaman EEG dengan pemberian melatonin dengan dosis : (1) BB 8-20 kg: 1,5 mg, (2) BB 20-30 kg: 3 mg, (3) BB 30-40 $\mathrm{kg}: 6 \mathrm{mg}$, (4) BB 30-70 kg: 9 mg.

Pemeriksaan EEG dilakukan sesuai standar internasional. Komponen yang dinilai selama perekaman adalah (1) Awitan tidur, yaitu dimulai saat lampu dimatikan sampai gelombang tidur EEG stadium 1 non-REM muncul, (2) Stadium tidur yang tercapai, (3) Lama tidur, yaitu dimulai saat muncul gelombang tidur EEG stadium 1 non-REM sampai gelombang tidur yang tampak pada monitor EEG hilang, (4) Ada tidaknya gelombang epileptiform selama perekaman.

Penilaian hasil EEG dilakukan oleh dua konsultan Divisi Neurologi IKA yang tidak mengetahui apakah pasien termasuk kelompok kontrol atau intervensi.

Setelah pemeriksaan EEG, selama 1 minggu dilakukan penilaian efek samping melatonin dengan menggunakan lembaran kuesioner dan komunikasi dengan orangtua pasien melalui telepon bila perlu.

\section{Hasil}

Selama penelitian terdapat 84 anak penyandang epilepsi yang memenuhi kriteria inklusi. Subyek dibagi menjadi dua kelompok, yaitu kelompok kontrol (DTP) 44 anak dan kelompok intervensi (melatonin) 40 anak. Delapan anak dinyatakan drop out karena tidak tampak keempat stadium tidur walaupun subyek tenang dan memejamkan mata. Kelompok drop-out ini, terdiri dari 5 anak dari kelompok DTP dan 3 anak dari kelompok melatonin sehingga didapatkan total subyek 39 anak dari kelompok DTP dan 37 anak dari kelompok melatonin. Dari 76 subyek, usia rata-rata kelompok kontrol 6,56 tahun dan kelompok intervensi 8,19 tahun. Tidak terdapat perbedaan yang bermakna antara 2 kelompok dalam hal usia rata-rata, jenis kelamin maupun jenis epilepsi.

Reliabilitas pengukuran awitan tidur, lama tidur, stadium tidur, timbulnya gelombang epileptiform antar 2 penilai.

Analisis awal dimulai dengan uji keandalan (reliabilitas) pengumpulan data. Data diperoleh dari penilaian awitan, lama dan stadium tidur yang dilakukan oleh 2 konsultan neuropediatri pada perekaman EEG masing-masing subyek. Uji keandalan memakai analisis Bland-Altman dan dinyatakan dengan Inter Correlation Coefficient (ICC), nilai ICC 0-6-0,8 mempunyai kriteria baik. Uji keandalan menunjukkan hasil sebagai berikut, (1) ICC awitan tidur pada kelompok DTP adalah 0,745, kelompok melatonin adalah 7,780, (2) ICC lama tidur pada kelompok DTP adalah 0,734, kelompok melatonin adalah 0,790. Uji Kappa untuk stadium tidur antar 2 penilai adalah 0,735 .

\section{Profil awitan tidur, lama tidur, dan stadium tidur}

Awitan tidur adalah timbulnya stadium tidur 1 nonREM yang terlihat pada gambaran EEG, dinyatakan dengan hitungan menit dan detik. Lama tidur dimulai saat terlihat gelombang tidur pada stadium 1 non-REM pada gambaran EEG sampai hilangnya gelombang tidur yang tampak pada monitor EEG, dinyatakan dengan hitungan menit dan detik. Rerata awitan tidur pada kelompok DTP 42,39 menit, sedangkan kelompok melatonin 33,97 menit dengan nilai $\mathrm{p}=0,001$. Pada kelompok DTP, rerata lama tidur 22,58 menit, sedangkan kelompok melatonin 25,09 menit dengan nilai $\mathrm{p}=0,144$ seperti tertera pada Tabel 1 .

Didapatkan penilaian makrostruktur tidur sebagai berikut, stadium 1 non-REM pada kelompok DTP ditemukan $31(79,5 \%)$ anak, sisanya $8(20,5 \%)$ anak tidak ditemukan, sedangkan pada kelompok melatonin ditemukan $32(85,5 \%)$ dan $5(13,5 \%)$ anak tidak ditemukan.

Pada stadium 2 non-REM kelompok DTP ditemukan $27(69,2 \%)$ anak, sisanya $12(30,8 \%)$ tidak 
Setyo Handryastuti dkk: Perbandingan melatonin dan prosedur deprivasi tidur untuk persiapan pemeriksaan EEG

Tabel 1. Pengukuran awitan dan lama tidur pada kelompok DTP dan melatonin

\begin{tabular}{lccccc}
\hline & \multicolumn{2}{c}{ DTP } & \multirow{2}{*}{ Melatonin } & \\
\cline { 2 - 4 } & Rerata (menit) & SB & Rerata (menit) & SB & \\
\hline Awitan tidur & 42,39 & 7,982 & 33,97 & 10,944 & 0,001 \\
Lama tidur & 22,58 & 8,168 & 25,09 & 4,980 & 0,144 \\
\hline
\end{tabular}

Makrostruktur tidur terdiri dari fase non-REM (stadium tidur 1-4) dan REM.

Tabel 2. Perbandingan makrostruktur tidur (stadium 1-4 non-REM) antara kelompok DTP dan kelompok melatonin

\begin{tabular}{lccccc}
\hline Stadium & $\begin{array}{c}\text { DTP } \\
(\mathrm{n}=39)\end{array}$ & $\begin{array}{c}\text { Melatonin } \\
(\mathrm{n}=37)\end{array}$ & RR & $95 \%$ CI & Nilai p \\
\hline 1 & $31 / 39$ & $32 / 37$ & 1,652 & $0,487-5,604$ & 0,418 \\
2 & $27 / 39$ & $29 / 37$ & 0,793 & $0,256-2,460$ & 0,688 \\
3 & $10 / 39$ & $9 / 37$ & 0,932 & $0,330-2,636$ & 0,895 \\
4 & $1 / 39$ & $1 / 37$ & 1,056 & $0,064-17,516$ & 0,970 \\
\hline
\end{tabular}

ditemukan. Pada kelompok melatonin, ditemukan 29 $(78,4 \%)$ anak dan $8(21,6 \%)$ tidak ditemukan.

Pada stadium 3 non-REM, jumlah anak yang ditemukan pada kelompok DTP $10(25,6 \%)$ anak, sedangkan yang tidak ditemukan $29(74,4 \%)$. Pada kelompok melatonin, $9(24,3 \%)$ anak ditemukan stadium 3 non-REM, sedangkan $28(75,7 \%)$ tidak ditemukan.

Pada stadium 4 non-REM, terdapat satu anak pada kelompok DTP $(2,6 \%)$ dan kelompok melatonin $(2,7 \%)$ seperti tertera pada Tabel 3. Perhitungan uji Chi-square memperlihatkan tidak terdapat perbedaan yang bermakna dari stadium tidur, seperti tertera pada Tabel 2.

Pada 8 dari 39 anak kelompok DTP ditemukan gelombang epileptiform, sedangkan kelompok melatonin ditemukan 7 dari 37 anak dengan perbedaan yang tidak bermakna.

Efek samping (kelelahan, vertigo, mual, muntah, nyeri kepala, rewel, dan kejang) didapatkan tidak berbeda secara bermakna $(p>0,05)$, baik pada kelompok DTP maupun kelompok melatonin seperti tertera pada Tabel 3.

Rerata lama tidur malam setiap hari dalam kelompok DTP 8,15 jam, sedangkan kelompok melatonin 8,41 jam dengan nilai $\mathrm{p}=0,438$. Pada penelitian ini, $34(87,2 \%)$ subyek yang dilakukan prosedur DTP mengalami kesulitan untuk tetap terjaga penuh saat malam hari. Hal ini bertolak belakang dengan kelompok melatonin karena tidak dilakukan upaya terjaga penuh di malam hari pada kelompok ini sebagai salah satu langkah persiapan pemeriksaan EEG. Keluhan mengantuk setelah pemeriksaan tidak berbeda secara bermakna pada kelompok DTP dan melatonin dengan nilai $\mathrm{p}=0,995$ seperti tertera pada Tabel 4 .

Dari total 39 subyek pada kelompok prosedur DTP, 5 subyek mengalami penundaan pemeriksaan EEG pada kedatangan pertama ke rumah sakit. Penundaan pemeriksaan EEG disebabkan pasien tidak berhasil tidur saat akan dilakukan pemeriksaan EEG. Pemeriksaan kemudian berhasil dilakukan pada kunjungan kedua ke rumah sakit, yang sebelumnya telah dilakukan edukasi ulang kepada orangtua mengenai persiapan prosedur DTP. Berbeda dengan kelompok melatonin, seluruh subyek kelompok ini berhasil melakukan pemeriksaan EEG pada kunjungan pertama ke rumah sakit.

\section{Pembahasan}

Kelebihan penelitian ini adalah merupakan penelitian pertama di Indonesia yang menggunakan melatonin sebagai premedikasi untuk pemeriksaan EEG pada pasien epilepsi anak. Penelitian ini juga menggunakan metode uji prospektif tersamar tunggal dan menilai uji keandalan (reliabilitas) antara ke-2 pengamat.

Induksi tidur sebagai persiapan EEG pada anak diperlukan dan sampai saat ini masih sulit dilakukan dengan cara alamiah. Penggunaan obat-obat sedasi, 
Setyo Handryastuti dkk: Perbandingan melatonin dan prosedur deprivasi tidur untuk persiapan pemeriksaan EEG

Tabel 3. Efek samping prosedur DTP dibandingkan premedikasi melatonin

\begin{tabular}{|c|c|c|c|c|c|}
\hline \multirow{2}{*}{ Efek samping } & \multicolumn{2}{|c|}{ DTP } & \multicolumn{2}{|c|}{ Melatonin } & \multirow{2}{*}{$\mathrm{p}$} \\
\hline & $\mathrm{N}$ & $\%$ & $\mathrm{~N}$ & $\%$ & \\
\hline \multicolumn{6}{|l|}{ Kelelahan } \\
\hline Tidak & 35 & 89,7 & 35 & 94,6 & 0,433 \\
\hline $\mathrm{Ya}$ & 4 & 10,3 & 2 & 5,4 & \\
\hline \multicolumn{6}{|l|}{ Vertigo } \\
\hline Tidak & 20 & 51,3 & 21 & 56,8 & 0,877 \\
\hline Ya & 2 & 5,1 & 2 & 5,4 & \\
\hline TDD & 17 & 43,6 & 14 & 37,8 & \\
\hline \multicolumn{6}{|l|}{ Mual } \\
\hline Tidak & 33 & 84,6 & 36 & 97,3 & 0,056 \\
\hline Ya & 6 & 15,4 & 1 & 2,7 & \\
\hline \multicolumn{6}{|l|}{ Muntah } \\
\hline Tidak & 38 & 97,4 & 35 & 94,6 & 0,525 \\
\hline Ya & 1 & 2,6 & 2 & 5,4 & \\
\hline \multicolumn{6}{|l|}{ Nyeri kepala } \\
\hline Tidak & 22 & 56,4 & 25 & 67,6 & 0,514 \\
\hline $\mathrm{Ya}$ & 4 & 10,3 & 4 & 10,8 & \\
\hline TDD & 13 & 33,3 & 8 & 21,6 & \\
\hline \multicolumn{6}{|l|}{ Rewel } \\
\hline Tidak & 39 & 100 & 35 & 94,6 & 0,141 \\
\hline Ya & 0 & & 2 & 5,4 & \\
\hline \multicolumn{6}{|c|}{ Mengalami kejang } \\
\hline Tidak & 35 & 89,7 & 34 & 91,9 & 0,746 \\
\hline $\mathrm{Ya}$ & 4 & 10,3 & 3 & 8,1 & \\
\hline
\end{tabular}

TDD = Tak dapat dinilai

Tabel 4. Akseptabilitas pemeriksaan EEG antara prosedur DTP dan premedikasi melatonin bagi orangtua

\begin{tabular}{lcccccc}
\hline \multirow{2}{*}{ Akseptabilitas } & \multicolumn{3}{c}{ DTP } & \multicolumn{3}{c}{ Melatonin } \\
\cline { 2 - 6 } & $\mathrm{N}$ & $\%$ & $\mathrm{~N}$ & $\%$ & $\mathrm{p}$ \\
\hline Kesulitan tetap terjaga penuh saat malam hari & & & & & \\
$\quad$ Tidak & 5 & 12,8 & 37 & 100 & 0,024 \\
$\quad$ Ya & 34 & 87,2 & 0 & 0 & \\
Mengantuk & & & & & \\
$\quad$ Tidak & 19 & 48,7 & 18 & 48,6 & 0,995 \\
$\quad$ Ya & 20 & 51,3 & 19 & 51,4 & \\
\hline
\end{tabular}

seperti golongan klorpromazin, kloralhidrat, dan benzodiazepin yang sebelumnya digunakan untuk menginduksi tidur dapat memengaruhi makrostruktur tidur, timbulnya gelombang epileptiform, serta mengganggu interpretasi data rekaman EEG. ${ }^{5-7}$ Tidur yang alamiah adalah kondisi tidur yang paling ideal karena melalui tahapan tidur yang baik. Hal ini menjadi dasar munculnya penelitian mengenai obat nonsedatif yang dapat menjadi pilihan premedikasi pemeriksaan EEG pada anak, salah satunya adalah melatonin.

Pada penelitian ini didapatkan awitan tidur yang lebih cepat pada kelompok melatonin dibandingkan dengan kelompok DTP sesuai dengan penelitian yang dilakukan oleh Wassmer dan Eisermann. ${ }^{5,6,8}$ Awitan tidur pada kelompok melatonin dicapai pada menit ke- 
Setyo Handryastuti dkk: Perbandingan melatonin dan prosedur deprivasi tidur untuk persiapan pemeriksaan EEG

34, sedangkan pada kelompok DTP pada menit ke-42. Hal ini tentu sangat membantu karena teknisi maupun orangtua tidak memerlukan waktu yang lama untuk memulai perekaman EEG. Penelitian Ashrafi dkk ${ }^{10}$ yang membandingkan pemberian kloralhidrat dan melatonin juga melaporkan perbedaan bermakna median waktu yang dibutuhkan untuk terjadinya awitan tidur pada kedua kelompok, yaitu 60 menit dan 30 menit secara berurutan, dan gambaran gelombang epileptiform terdeteksi lebih tinggi pada pemberian melatonin. Hal ini sesuai dengan hasil penelitian ini, awitan tidur lebih cepat tercapai dengan penggunaan melatonin sehingga mempermudah pelaksanaan pemeriksaan EEG.

Pada makrostruktur tidur didapatkan hasil tidak berbeda bermakna antara kelompok DTP dan kelompok melatonin pada semua stadium tidur, mulai dari stadium 1 sampai 4 non-REM. Hal ini sangat membantu karena dengan adanya gambaran EEG transisi antara sadar dan stadium 1 (drowsy) maupun transisi dari tidur ke sadar (arousal) gambaran gelombang epileptiform lebih sering ditemukan dan sangat membantu untuk diagnosis dan klasifikasi epilepsi, serta menentukan fokus kejang dan penyebarannya. Seluruh stadium tidur yang dialami subyek penelitian ini sesuai dengan hasil penelitian Wassmer dan Dijk. ${ }^{6,8,11}$

Makrostruktur tidur sesuai dengan tidur alami dan diperoleh stadium 1 dan 2 yang dapat menyebabkan munculnya gelombang epileptiform. Pada pemeriksaan EEG dengan premedikasi obat-obat sedatif, seperti klorpromazin, kloralhidrat, dan benzodiazepin, pasien langsung masuk ke stadium 3 sehingga sulit diperoleh gambaran gelombang epileptiform sesuai dengan penelitian Ashraf ${ }^{10}$ yang membandingkan pemberian melatonin dan kloralhidrat. Berdasarkan hal tersebut, peneliti dapat menyimpulkan bahwa pemberian melatonin tidak berbeda bermakna dengan prosedur DTP maupun tidur alamiah untuk mendapatkan hasil EEG yang ideal.

Anak umumnya dibiarkan tidur selama kurang lebih 20 menit pada pemeriksaan EEG, selanjutnya dibangunkan untuk pemeriksaan stimulasi fotik dan hiperventilasi (jika sudah dapat melakukan). ${ }^{12}$ Pada penelitian ini penilaian lama tidur pada kelompok DTP dibandingkan dengan kelompok melatonin yang mempunyai nilai hampir sama, yaitu berturut-turut 22,58 dan 25,09 menit. Waktu tersebut cukup dan sesuai dengan kebutuhan tidur selama pemeriksaan EEG. ${ }^{5,6}$
Pengamatan terhadap efek samping (kelelahan, rewel, vertigo, nyeri kepala, mual, muntah, kejang, dan mengantuk setelah pemeriksaan EEG) didapatkan tidak berbeda secara bermakna antara kelompok DTP dan kelompok melatonin. Hal tersebut sesuai dengan penelitian sebelumnya yang menyatakan tidak ada perbedaan bermakna kejadian efek samping antara prosedur DTP dengan pemberian melatonin..$^{5-10}$

Pemberian melatonin sendiri memiliki keunggulan karena orangtua tidak dipersulit dengan upaya membuat anak terjaga penuh saat malam hari. ${ }^{5,6,8}$ Kelebihan pemberian melatonin juga didapatkan dari angka kejadian penundaan pemeriksaan EEG pada kelompok DTP. Hal ini dibuktikan dari terdapatnya 5 subyek dari kelompok DTP yang mengalami penundaan pemeriksaan EEG akibat anak gagal mengalami proses tidur pada kedatangan pertama ke rumah sakit. Orangtua akhirnya harus membawa anak dua kali ke rumah sakit untuk pemeriksaan dan menyebabkan kerugian dari sisi biaya. Hal ini sangat berlawanan dengan kelompok melatonin yang tidak mengalami satupun kegagalan pun dalam pemeriksaan EEG di kunjungan pertama ke rumah sakit.

Lama tidur tiap malam pada kelompok DTP dan melatonin kurang lebih sama pada subyek penelitian ini. Keadaan ini mencerminkan bahwa anak yang merupakan subyek penelitian ini secara keseluruhan tidak mengalami kesulitan tidur. Hal ini menggambarkan homogenitas subyek penelitian, Gangguan tidur sebelumnya tidak memengaruhi hasil penelitian. Untuk gelombang epilepsi didapatkan jumlah yang hampir sama antara kelompok DTP dan melatonin sesuai dengan penelitian Wassmer. ${ }^{6,8}$

\section{Kesimpulan}

Penggunaan premedikasi melatonin dapat menjadi pilihan untuk persiapan pemeriksaan EEG pada anak. Hal ini didukung dengan cepat terjadinya awitan tidur, tidak berbedanya makrostruktur tidur dengan prosedur DTP yang merupakan gambaran tidur alamiah, tercapainya lama tidur yang cukup untuk durasi pemeriksaan EEG, serta orangtua tidak mengalami kesulitan dalam persiapan pemeriksaan EEG, seperti prosedur DTP. Efek samping yang timbul akibat pemberian melatonin juga tidak berbeda bermakna dengan prosedur DTP sehingga tidak muncul kekhawatiran akan reaksi yang mungkin terjadi. 


\section{Daftar pustaka}

1. Niedermeyer E. Epileptic seizure disorder. Dalam: Niedermeyer E, Lopes Da Silva FH, penyunting. Electroencephalography: Basic principles, clinical application, and related fields. Edisi ke-4. Baltimore: Williams \& Wilkins;1999.h. 476-80.

2. Pearl PL. Overview of seizures and epilepsy in children. Dalam: Swaiman KF, Ashwal S, Ferriero DM, Schor NF, Finkel RS, Gropman AL, penyunting. Pediatric neurology: principles and practise. Philadelphia: Mosby-Elsevier;2017. h.497-500.

3. Stafstrom CE. The pathophysiology of epileptic seizure: a primer for pediatrician. Pediatr Rev 1998;19:342-51.

4. Nizmah. EEG normal. Dalam: Syeban Z, Octaviana F, Budikayanti A, penyunting. EEG praktis. Edisi ke-2. Jakarta: Badan Penerbit FKUI;2015.h.33-52.

5. Eisermann M, Kaminska A, Berdougo B, Brunet ML. Melatonin: experience in its use for recording EEG in children and review of the literature. Neuropediatrics 2010;41:163-6.

6. Wassmer E, Quinn E, Whitehouse W, Seri S. Melatonin as a sleep inductor for electroencephalogram recordings in children. Clin Neurophysiol. 2001;112:683-5.

7. Sander J, Shamdeen MG, Gottschling S, Gortner L, Graber
S, Meyer S. Melatonin does not influence sleep deprivation electroencephalogram recordings in children. Eur J Pediatr 2012;171:675-9.

8. Wassmer E, Carter PF, Quinn E, McLean N, Welsh G, Seri S, dkk. Melatonin is useful for recording sleep EEGs: a prospective audit of outcome. Dev Med Child Neurol 2001;43:735-8.

9. Gustafsson G, Brostrom A, Ulander M, Vrethem M, Svanborg E. Occurence of epileptiform discharges and sleep during EEG recordings in children after melatonin intake versus sleepdeprivation. Clin Neurophysiol 2015;126:1493-7.

10. Ashrafi MR, Mohammadi M, Tafarroji J, Shabanian R, Salamati P, Zamani GR. Melatonin versus chloral hydrate for recording sleep EEG. Eur J Paediatr Neurol 2010;14:235-8.

11. Dijk DJ, Cajochen C. Melatonin and the circadian regulation of sleep initiation, consolidation, structure and sleep EEG. J Biol Rhythms 1997;12:627-35.

12. Niedermeyer E. Maturation of the EEG: development of waking and sleep patterns. Dalam: Niedermeyer E, Lopes Da Silva FH, penyunting. Electroencephalography: basic principles, clinical application, and related fields. Edisi ke-4. Baltimore: Williams \& Wilkins;1999.h.189-214. 